\title{
Letter to the editor: immediate implications of improved surgical efficiency
}

Daniel Gologorsky'
Timothy G Murray',2

'Bascom Palmer Eye Institute, Anne Bates Leach Eye Hospital, University of Miami Miller School of Medicine, Miami, FL, USA; ${ }^{2}$ Murray Ocular Oncology and Retina, Miami, FL, USA
Correspondence: Timothy G Murray Murray Ocular Oncology and Retina, 6705 Red Road, Suite 412, Miami, FL 33।43, USA

Email tmurray@murraymd.com

\author{
This article was published in the following Dove Press journal: \\ Clinical Ophthalmology \\ 4 December 2013 \\ Number of times this article has been viewed
}

\section{Dear editor}

Earlier this year we published our analysis regarding the improved surgical efficiencies that commenced with the transition from the Accurus (Alcon Surgical, Fort Worth, TX, USA) to the Constellation Vision System (Alcon Surgical) integrated vitrectomy platform. ${ }^{1}$ The results of our study demonstrated that the transition to the Constellation platform resulted in an increase in the number of patient operations per day (from 7.55 to 8.53 , a $12.98 \%$ increase), with a concurrent and statistically significant decrease in surgical room time (occurring without compromise to patient evaluated outcomes). The ramifications of such changes on resource allocation and operations management have not been reported. This brief report will expound on the immediate implications of increased surgical efficiency.

As the index study was conducted in a large ophthalmology specialty hospital as part of a tertiary referral center, this discussion will focus on similar departments marked with historic long patient wait times, where demand is assumed to always exceed current capacity. With this notion in mind, standard queuing theory maintains that an improvement in surgical capacity should lead to a decrease in patient wait times if no other change is made to the system. Assuming there is some variability in arrival or service times, it is apparent that a reduction in wait time decreases the overall throughput time (TPT), as by definition throughput time equals the wait time (W) plus service time (M), both of which are reduced in this scenario. This decrease in patient wait times is a meaningful system performance measure alone, even without utilizing the excess capacity for more surgeries.

Notwithstanding, such surgical capacity improvement can also generate revenues by either increasing the volume of similar vitrectomy procedures (where the increase in capacity is utilized for more of the same type of procedure) or additional "other procedures" (where the excess capacity is dedicated to alleviate bottleneck stresses on traditional procedures or to more lucrative procedures other than the vitrectomy). In the first case, where the department chooses to pursue more of the same procedure, the increase in capacity improves the throughput rate (TPR) of similar vitrectomy procedures, implying more revenues as a direct function of the increased number of procedures. This assumes that again, demand exceeds capacity, and that on a unit basis the reimbursement for the vitrectomy procedure (revenue), discounting fixed and variable costs associated with the vitrectomy (total costs), yields a net positive value (profit). The second case suggests that the excess capacity generated by a decrease in surgical 
room time can also allow a department to accommodate an increased throughput rate of other procedures. From a business model, the hospital would have to determine the degree of revenue associated with these procedures, and prioritize accordingly. A profit maximizing strategy is one where the new procedures maximize revenue and minimize costs.

Perhaps the most important ramification of improved surgical capacity is the inherent possibility for enhanced efficiency. Decreased patient wait times is an important metric alone. Increased revenues can be shunted toward alleviating bottlenecks in production by hiring new surgeons or additional Constellation platforms. Alternatively, additional capacity can be directed towards freeing shared resources. Thus, the benefits of innovation and improved efficiency are manifold, and can be applied to improve quality of patient care, increase revenues, decrease costs, improve employee conditions, or provide a valuable marketing opportunity. We believe that an understanding of the impact of operational management principles (in this case, queuing theory) will enable surgeons and administrators to better evaluate the acquisition of, and transition to, new technologies, in order to ultimately enhance delivery of care to patients.

\section{Disclosure}

The authors report no conflicts of interest in this communication.

\section{Reference}

1. Murray TG, Layton AJ, Tong KB, et al. Transition to a novel advanced integrated vitrectomy platform: comparison of the surgical impact of moving from the Accurus vitrectomy platform to the Constellation Vision System for microincisional vitrectomy surgery. Clin Ophthalmol. 2013;7:367-377.
Clinical Ophthalmology

\section{Publish your work in this journal}

Clinical Ophthalmology is an international, peer-reviewed journal covering all subspecialties within ophthalmology. Key topics include: Optometry; Visual science; Pharmacology and drug therapy in eye diseases; Basic Sciences; Primary and Secondary eye care; Patient Safety and Quality of Care Improvements. This journal is indexed on

\section{Dovepress}

PubMed Central and CAS, and is the official journal of The Society of Clinical Ophthalmology (SCO). The manuscript management system is completely online and includes a very quick and fair peer-review system, which is all easy to use. Visit http://www.dovepress.com/ testimonials.php to read real quotes from published authors. 